\section{International Scientific Journal Theoretical \& Applied Science}

p-ISSN: 2308-4944 (print) e-ISSN: 2409-0085 (online)

$\begin{array}{lll}\text { Year: } 2016 \quad \text { Issue: } 7 & \text { Volume: } 39\end{array}$

Published: $30.07 .2016 \quad$ http://T-Science.org
S.G. Nezdoyminov

$\mathrm{PhD}$, Associate Professor of the Department of Economic and management of tourism Odessa National Economic University

\section{K.V. Zakladna}

Mgr,

Department of Economic and management of tourism Odessa National Economic University karina-zakladna@mail.ru

SECTION 34. Tourism.

\title{
STATE AND PROSPECTS OF DEVELOPMENT OF TOURISM INFRASTRUCTURE IN THE ODESSA REGION
}

\begin{abstract}
This article studied the modern tourist infrastructure of the Odessa region. It examines a tourist and recreational potential of the Odessa region. The analysis of the development of the hotel industry in the Odessa region. It characterizes by the dynamics of tourist flows in Odessa region for 2012-2015 years. Article describes the problems and prospects of development of tourism infrastructure of the Odessa region.

Key words: infrastructure, tourism potential, resources, accommodation facilities, tourist flow.

Language: Russian

Citation: Nezdoyminov SG, Zakladna KV (2016) STATE AND PROSPECTS OF DEVELOPMENT OF TOURISM INFRASTRUCTURE IN THE ODESSA REGION. ISJ Theoretical \& Applied Science, 07 (39): 65-69. Soi: http://s-o-i.org/1.1/TAS-07-39-11 Doi: crossef http://dx.doi.org/10.15863/TAS.2016.07.39.11 \section{ОДЕССКОГО РЕГИОНА}

СОСТОЯНИЕ И ПЕРСПЕКТИВЫ РАЗВИТИЯ ТУРИСТИЧЕСКОЙ ИНФРАСТРУКТУРЫ

Аннотация: В статье изучена современная туристическая инфраструктура Одесского региона. Раскрыт туристско-рекреационный потенциал Одесского региона. Проведен анализ развития гостиничной индустрии в Одесском регионе. Охарактеризована динамика туристических потоков Одесского региона за 2012-2015 г2. Рассмотрены проблемы и перспективы развития туристической инфраструктуры Одесского региона.

Ключевые слова: инфраструктура, туристический потенцииал, ресурсы, средства размещения, туристический поток.
\end{abstract}

\section{Введение}

Туристическая инфраструктура играет важную роль в формировании устойчивого развития туризма. По своему курортнорекреационному и туристическому потенциалу Одесская область занимает одно из ведущих мест в Украине. В то же время в регионе недостаточно уделяется внимание проблемам модернизации и развития туристической инфраструктуры.

Проблемы развития потенциала туристической инфраструктуры региона исследовались в трудах отечественных специалистов: С. Г. Нездойминова [4, 5], Н. Е. Нефедовой, В. В. Яворской [6], В. Г. Герасименко [7], О. В. Шикиной [9] и др. Большинство исследователей считает, что эффективное использование рекреационных ресурсов возможно при наличии современной базы размещения туристов и экологизации туристической инфраструктуры.

В современной литературе туристическая инфраструктура рассматривается как совокупность предприятий, учреждений и организаций, деятельность которых направлена на удовлетворение потребностей людей, участвующих в оздоровлении или отдыхе, а также путей сообщения и транспорта, и объектов размещения туристов, обеспечивающих условия стабильного функционирования территорий [2]. Туристическая инфраструктура - это совокупность искусственно созданных рекреационных учреждений (санатории, базы отдыха, гостиницы, рестораны и др.). А также сопутствующих объектов, построенных для общего пользования за счет государственного инвестирования (автомобильные и железные дороги (пути), пункты пропуска, аэропорты, больницы, школы и т.д.) [1]. Соколова К. О. 
считает, что инфраструктура туризма - это комплекс сооружений и сетей, обеспечивающих нормальный доступ туристов к туристским ресурсам и их надлежащее использование в целях туризма [8].

Процесс развития индустрии туризма - это сложный и динамичный, многофакторный процесс, зависящий от многочисленных предпосылок и факторов, которые способствуют или ограничивают темпы развития туристической деятельности. По мнению исследователей, туризм развивается под влиянием факторов, присущих индустрии туризма: факторов функционирования рынка туристических услуг, формирования спроса и предложения, производства туристического продукта и т.д. А также факторов внешней среды - это государственная политика и регулирование в сфере туризма и рекреации, экономика и финансы (макроэкономические и микроэкономические факторы), культура, социальные и демографические изменения, развитие торговли, транспорта, инфраструктуры и научно-технического прогресса [3].

Одесский регион является одним из ведущих туристско-рекреационных регионов Украины, что обусловлено особенностью экономико-географического положения области, благоприятными природно-климатическими условиями, наличием различных природнолечебных ресурсов и песчаных морских пляжей.

Регион имеет 92 природно-заповедные зоны, в том числе государственного значения Дунайский биосферный заповедник, Дунайские и Днестровские плавни, ландшафтный парк "Тилигульский", ботанический сад Одесского национального университета им. И. И. Мечникова, 19 парков-памятников садовопаркового искусства, 2 заповедника. Среди многочисленных природных богатств области важное место занимают уникальные лечебные грязи, запас которых составляет почти 400 млн. м3 и минеральные воды: серно-водородные, гидро-карбонатные, йодо-бромные, натриевые, термальные и другие бальнеологические виды вод.

В настоящее время, туристическая инфраструктура области насчитывает 1292 объектов туристско-рекреационного и оздоровительного назначения, в том числе 296 гостиниц и аналогичных средств временного размещения туристов, 803 оздоровительнорекреационного назначения - санатории, базы отдыха, пансионаты, детские лагеря и более 300 туроператоров и турагентов, которые создают региональный туристический продукт. Туристическая инфраструктура области позволяет одновременно разместить более 104,0 тысяч туристов и отдыхающих в течение всего года. Если летом туристов привлекает отдых на морском побережье, то в зимний период Одесский регион позиционирует себя как центр делового туризма, поскольку с каждым годом увеличивается количество современных гостиничных комплексов с инфраструктурой и оборудованием для проведения бизнес-туров, конференций и семинаров.

Характеристика данных о динамике развития гостиниц и других средствах размещения играет важную роль в анализе состояния туристической отрасли Одесского региона, ведь именно совокупность средств размещения является ключевым сегментом в туристической индустрии. По данным Главного управления статистики в Одесской области, количество гостиниц и аналогичных средств размещения в 2015 году составило 250 объектов (табл. 1). Динамика их развития за 2012-2015 гг. представлена нами на рис. 1 [10].

\section{Количество коллективных средств размещения в Одесском регионе в 2012-2015 гг.}

\section{Таблица 1}

\begin{tabular}{|c|c|c|c|c|c|c|}
\hline & \multicolumn{3}{|c|}{$\begin{array}{c}\text { Количество коллективных средств } \\
\text { размещения, единиц }\end{array}$} & \multicolumn{3}{|c|}{ Количество размещенных, человек } \\
\hline & \multirow[t]{2}{*}{ всего } & \multicolumn{2}{|c|}{ в том числе } & \multirow[t]{2}{*}{ всего } & \multicolumn{2}{|c|}{ в том числе } \\
\hline & & $\begin{array}{c}\text { гостиниц и } \\
\text { аналогичных } \\
\text { средств } \\
\text { размещения }\end{array}$ & $\begin{array}{l}\text { специализированных } \\
\text { средств размещения }\end{array}$ & & $\begin{array}{c}\text { в гостиницах и } \\
\text { аналогичных } \\
\text { средствах } \\
\text { размещения }\end{array}$ & $\begin{array}{l}\text { в специализированных } \\
\text { средствах размещения }\end{array}$ \\
\hline 2012 & 623 & 216 & 407 & 545661 & 246935 & 298726 \\
\hline 2013 & 685 & 253 & 432 & 567678 & 295298 & 272380 \\
\hline 2014 & 629 & 235 & 394 & 390554 & 181282 & 209272 \\
\hline 2015 & 647 & 250 & 397 & 471515 & 240586 & 230929 \\
\hline
\end{tabular}




\begin{tabular}{l|lr|ll|ll} 
& ISRA (India) & $=\mathbf{1 . 3 4 4}$ & SIS (USA) & $=\mathbf{0 . 9 1 2}$ & ICV (Poland) & $=\mathbf{6 . 6 3 0}$ \\
Impact Factor: & ISI (Dubai, UAE) $=\mathbf{0 . 8 2 9}$ & PUHI (Russia) & $=\mathbf{0 . 2 3 4}$ & PIF (India) & $=\mathbf{1 . 9 4 0}$ \\
& GIF (Australia) & $=\mathbf{0 . 5 6 4}$ & ESJI (KZ) & $=\mathbf{1 . 0 4 2}$ & IBI (India) & $\mathbf{4 . 2 6 0}$ \\
& JIF & $\mathbf{1 . 5 0 0}$ & SJIF (Morocco) & $\mathbf{2 . 0 3 1}$ & & \\
\hline
\end{tabular}

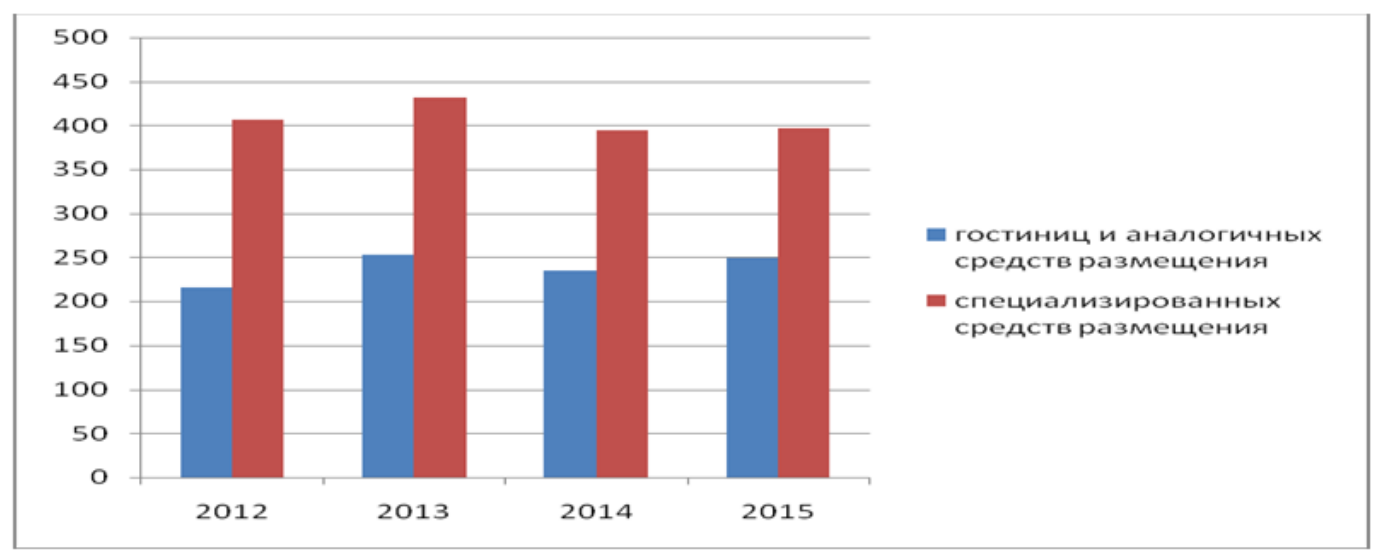

Рисунок 1 - Динамика развития коллективных средств размещения в Одесском регионе в 2012-2015 гг. [10]

Одесская область - один из немногих регионов Украины, который имеет значительный потенциал в сфере развития морского и речного круизного туризма, яхтенного туризма. И речь идет не только о природных возможностях наличие морского и речного побережья, но и о наличии соответствующих инфраструктурных объектов. Так, сегодня Одесский порт единственный порт в Украине, причальные сооружения которого позволяют принимать пассажирские круизные лайнеры длиной более 200 метров. Морские порты региона находятся на перекрестке международных транспортных коридоров. Анализ проблем развития круизного рынка показал, что для успешного функционирования морского туризма необходимо комплексное развитие всех элементов круизного судоходства и соответствующей ему региональной туристической инфраструктуры. За последние пять лет количество судозаходов в порты Украины выросло на $40 \%$, а количество пассажиров - на 53,4\%. Чаще всего черноморский регион посещают туристы из Германии, Великобритании и Италии. Доля круизных туристов из стран СНГ по портам Украины составляет 6,1\%, а например, в 2012 году была менее $1 \%$. Как считают эксперты, низкая эффективность реализации программ развития круизного бизнеса и модернизации морской инфраструктуры обусловлены недостаточным притоком инвестиций, связанными с неблагоприятным инвестиционным климатом в Украине в целом. Необходимо проводить системную работу по увеличению судозаходов иностранных круизных судов в порт Одесса. Отметим, что в 2013 году Одессу посетило рекордное количество круизных лайнеров - 106. Эта цифра стала самой крупной за всю историю независимости Украины. В 2014 году в Одессу планировали зайти еще больше иностранных лайнеров - 159. Однако сложная политическая и экономическая ситуации в Украине привела к отмене рейсов международных круизных операторов. В результате город посетили только 32 круизных лайнеров. На 2015 год было подано более 80 заявок, однако зашло 13 круизных лайнеров. В 2016 году посетить Одессу планируют 36 круизных лайнеров. Перспективы развития круизного бизнеса в регионе обсуждались на Генеральной Ассамблеи Ассоциации морских круизных портов MEDCRUISE (Одесса, 2016) [7].

В тоже время проведенные исследования указывают на уменьшение потока общего количества туристов в Одесском регионе в последние годы. Только в 2015 году происходит увеличение потока туристов. В 2013 году общее количество туристов по сравнению с 2012 годом уменьшилась на 5,4\%. В 2014 году по сравнению с 2013 годом наблюдается уже достаточно существенное снижение - 29,6\%. В 2015 году в сравнении с 2014 годом туристический поток увеличился на $5,5 \%$ (рис. 2). 


\begin{tabular}{l|lr|ll|ll} 
& ISRA (India) & $=\mathbf{1 . 3 4 4}$ & SIS (USA) & $=\mathbf{0 . 9 1 2}$ & ICV (Poland) & $=\mathbf{6 . 6 3 0}$ \\
Impact Factor: & ISI (Dubai, UAE) $=\mathbf{0 . 8 2 9}$ & PUHI (Russia) & $=\mathbf{0 . 2 3 4}$ & PIF (India) & $=\mathbf{1 . 9 4 0}$ \\
& GIF (Australia) & $=\mathbf{0 . 5 6 4}$ & ESJI (KZ) & $=\mathbf{1 . 0 4 2}$ & IBI (India) & $\mathbf{4 . 2 6 0}$ \\
& JIF & $\mathbf{1 . 5 0 0}$ & SJIF (Morocco) & $\mathbf{2 . 0 3 1}$ & & \\
\hline
\end{tabular}

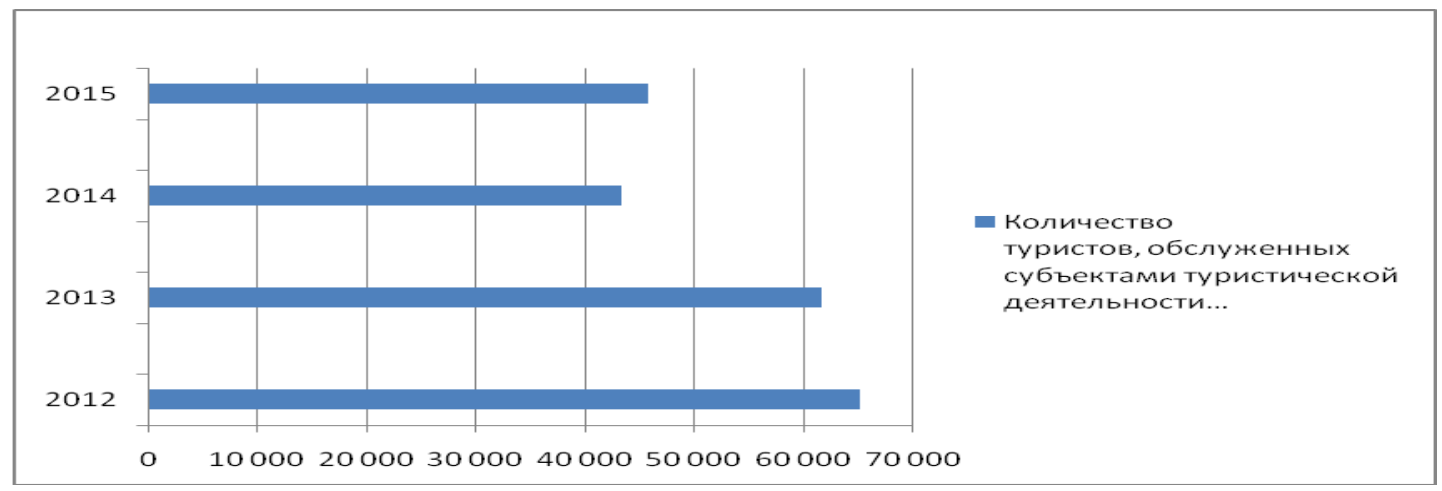

\section{Рисунок 2 - Количество туристов, обслуженных субъектами туристической деятельности в} Одесском регионе [10]

Наибольшее количество туристов посещает административный центр Одесской области Одессу. Ведь город, кроме туристической атрактивности, обладает также необходимой туристической инфраструктурой, которой, к сожалению, не обладают другие города Одесского региона (например, Черноморск, Белгород-Днестровский, Арциз, Измаил). Несмотря на то, что туристический поток в целом по региону снижался, туристский поток в Одессу характеризуется положительной динамикой. Основные перспективы дальнейшего увеличения потока туристов, по нашему мнению, будут связанны с развитием особых экономических зон туристскорекреационного типа. В 2015 году Одессу посетили более 1,5 миллиона туристов. Одессу стали активнее посещать туристы из Восточной и Западной Европы. Но основным был внутренний туристический поток туристов из разных регионов Украины.

Повышению

туристической привлекательности города способствовало улучшение туристической инфраструктуры и комплексное благоустройство Одессы. Из других городов Украины в Одессу были запущены дополнительные поезда, открытые бюджетные прямые авиарейсы. Информация об Одессе размещена в популярных украинских и международных изданиях, проведены рекламные туры для представителей украинских и зарубежных СМИ, туристических операторов и агентств [11].

Отметим, что наряду с позитивными тенденциями в развитии туристического потенциала, Одесский регион имеет ряд проблем, связанных с модернизацией туристической инфраструктуры. А именно: плохое качество дорог, отсутствие указателей (особенно на иностранном языке), отсутствие велосипедных дорожек, слабое развитие туристско-информационных центров в рекреационных районах и малых городах региона, отсутствие системных мер, направленных на сертификацию услуг по размещению туристов.

\section{Выводы}

Основной целью развития туристической инфраструктуры является формирование на территории Одесского региона современного эффективного туристического комплекса в соответствии с международными требованиями. Это приведет к дополнительным возможностям региона в удовлетворении потребностей в туристических услугах, как граждан Украины, так и зарубежных туристов. Обеспечит рост государственного и местного бюджетов за счет притоков иностранного капитала, создание дополнительных рабочих мест в регионе. Проведенные исследования позволяют сделать вывод о том, что туристическая инфраструктура Одесского региона в настоящее время не удовлетворяет в полном объеме спрос на туристические и сопутствующие услуги. Процессы регионального развития экономики, динамика организованного и индивидуального туризма в регионе, убеждает в необходимости разработки комплексной региональной стратегии по развитию туристической инфраструктуры и привлечению дополнительных инвестиций. 


\begin{tabular}{l|lrl|l|ll} 
& ISRA (India) & $=\mathbf{1 . 3 4 4}$ & SIS (USA) & $=\mathbf{0 . 9 1 2}$ & ICV (Poland) & $=\mathbf{6 . 6 3 0}$ \\
Impact Factor: & ISI (Dubai, UAE) $=\mathbf{0 . 8 2 9}$ & PUHU (Russia) $=\mathbf{0 . 2 3 4}$ & PIF (India) & $=\mathbf{1 . 9 4 0}$ \\
& GIF (Australia) & $\mathbf{0 . 5 6 4}$ & ESJI (KZ) & $=\mathbf{1 . 0 4 2}$ & IBI (India) & $\mathbf{4 . 2 6 0}$
\end{tabular}

\section{References:}

1. Gajduk AB (1999) Formuvannja turistichnoï rinkovoï infrastrukturi jak faktor pidvishhennja efektivnosti funkcionuvannja rinku turistichnih poslug / A. B. Gajduk // Regional'na ekonomika. - 1999. - №2. - pp.172-177.

2. Kuzik SP (2011) Geografija turizmu : navchal'nij posibnik / S. P. Kuzik. - K. : Znannja, 2011.

3. Mal's'ka MP, Antonjuk NV, Ganich NM (2008) Mizhnarodnij turizm i sfera poslug / M. P. Mal's'ka, N. V. Antonjuk, N. M. Ganich. - K. : Znannja, 2008. - $661 \mathrm{p}$.

4. Nezdojminov SG (2015) Potencial rozvitku turizmu v Odes'komu regioni / S. G. Nezdojminov // Finansovi aspekti rozvitku derzhavi, regioniv ta sub'ektiv gospodarjuvannja: suchasnij stan ta perspektivi: zbirnik materialiv I Mizhnarodnoï naukovopraktichnoï konferenciï m. Odesa 25-26 grudnja 2015 roku. - Odessa: Bondarenko M. O., 2015. - pp. 316-319.

5. Nezdojminov SG (2014) Turisticheskij potok faktor konkurentosposobnosti regiona / S. G. Nezdojminov // ARS ADMINISTRANDI: №3. - Perm' : PGINU, 2014. - pp. 78-83.

6. Nefedova NE, Javors'ka VV (2009) Chinniki rozvitku i resursi suchasnogo turizmu Odes'kogo regionu // Kul'tura narodov
Prichernomor'ja. - 2009. - № 176. - pp. 103107.

7. (2013) Rinki turistichnih poslug: stan i tendenciï rozvitku : monografija / za zag. red. profesora V. G. Gerasimenko. - Odesa : Astroprint, 2013. - 334 p.

8. Sokolova KO (2010) Upravlinnja turistichnim potencialom pidpriemstv / K.O. Sokolova // Visnik Hmel'nic'kogo nacional'nogo universitetu. - 2010. - №3. - T.1. - pp.208-210.

9. Shikina OV (2015) Analiz strukturi turistichnih potokiv Odes'koi oblasti / O. V. Shikina, I. L. Liptuga // Global'ni ta nacional'ni problemi ekonomiki - Redakcija elektronnogo naukovogo fahovogo vidannja. - Mikolaiv, 2015. - Vipusk №7. - pp. 114-127.

10. (2016) Golovne upravlinnja statistiki v Odes'kij oblasti. Turistichni potoki 2012-2015 rr. - [ Elektronnij resurs] - Available: http://www.od.ukrstat.gov.ua/ (Accessed: 10.07.2016).

11. (2016) Oficijnij sajt mista Odesi. $-\mathrm{Z}$ pochatku roku Odesu vidvidali bil'she 1,5 mil'jona turistiv. [Elektronnij resurs] - Available:: http://omr.gov.ua/ru/news/76552/ (Accessed: 10.07.2016) 